\title{
Loading mode of a ferromagnetic current stabilizer
}

\author{
A $N$ Rasulov ${ }^{1}, M R$ Ruzinazarov ${ }^{1}, N L$ Novikov $^{2}, G N$ Aslanova ${ }^{4}$, Esemuratova $^{3}$ \\ ${ }^{1}$ Tashkent state technical university named after Islam Karimov, Tashkent, Uzbekistan \\ ${ }^{2}$ National Research University Moscow Power Engineering Institute \\ ${ }^{3}$ Karakalpak State University \\ ${ }^{4}$ Bukhara Engineering Technological Institute
}

\begin{abstract}
The article discusses the analysis of the steady-state mode of a ferrimagnetic current stabilizer with active-inductive and active-capacitive loads, for assessing energy and operational indicators. The constructed adjustment characteristics determine the zone of stabilizations, which depend on the parameters of the device.
\end{abstract}

\section{Introduction}

In order to clarify the influence of various load parameters on the operation of the ferrimagnetic current stabilizer and to assess the energy and performance indicators, we will consider the load mode of the device. Taking assumptions and neglecting losses in the magnetic amplifier, we will analyze the steady state for active, activeinductive and active-capacitive loads [1-7].

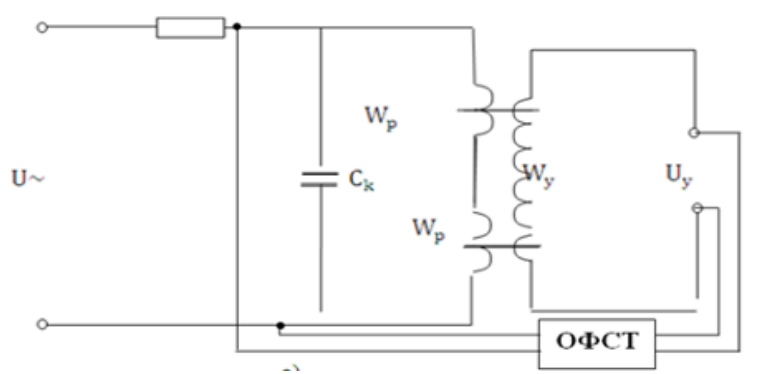

Fig. 1. Schematic diagram of a ferromagnetic current stabilizer

The equation of the electrical state of the circuit (Fig.1) for an active load is as follows:

$$
u_{c}=R_{H}\left(i_{c}+i_{\phi \ni}\right)+2 W_{p} \frac{d \Phi}{d t},
$$

where $u_{c}-$ mains voltage, $i_{c}-$ current flowing through the capacitor $\mathrm{C}_{\mathrm{K}}$

Let us assume that the magnetization curve of a ferromagnetic element is approximated by a power function, [8-14] then

$$
i_{p} w_{p}+i_{y} w=k b^{n}
$$

After introducing dimensionless quantities, taking into account (1) and (2), we have: $y=\delta\left(\frac{1}{m} \frac{d^{2} x}{d \tau^{2}}+i_{\phi \ni}\right)+2 W_{p} \frac{d \phi}{d t}$

Here

$$
\begin{gathered}
z+z_{0}=x^{n} \\
z=\frac{i}{i_{\sigma}} ; z=\frac{i_{y}}{i_{\sigma}} ; i_{\sigma}=\frac{k \Phi_{\sigma}^{n}}{w} ; x=\frac{\Phi}{\Phi_{\sigma}} ; \\
z_{c}=\frac{1}{m} \frac{d^{2} x}{d \tau^{2}} \\
\delta=\frac{R_{H} i_{\delta}}{2 \omega W \phi_{\delta}} ; m=\frac{i_{\delta}}{2 \omega^{2} W C_{k} \phi_{\delta}} ; X=\frac{\Phi}{\phi_{\delta}} ; \\
y=\frac{U c}{U_{\delta}} ; z=\frac{i}{i_{\delta}} ; U_{\delta}=2 \omega W \Phi_{\delta} \\
y=Y_{m} \cos (\tau+\varphi) \\
x=X_{m} \sin \tau \\
z=Z_{m} \sin \tau
\end{gathered}
$$

From (3), after some trigonometric transformations, we obtain

$$
\begin{gathered}
\mathrm{y}_{m}^{2}=X_{m}^{2}+\delta^{2}\left(Z_{m}-\frac{X_{m}}{m}\right)^{2} \\
\operatorname{tg} \varphi=\frac{\delta\left(\frac{X_{m}}{m}-Z_{m}\right)}{X_{m}}
\end{gathered}
$$


For further mathematical analysis, it is necessary to analytically express the characteristic $X_{m}=f\left(Z_{m}\right)$. In this case, it is convenient to take an approximating function of the following form:

$$
X_{m}=a Z_{m}^{4}
$$

This dependence qualitatively describes the characteristic of simultaneous magnetization in the working section of the magnetic amplifier in the stabilization mode and gives rather simple results for analyzing the load mode of the device. The value of the coefficient depends on the magnitude of the bias current, and it can be determined by the method of selected points or by the method of least squares [15-22].

Substituting (6) into (4), we have:

$$
Y_{m}^{2}=a^{2} Z_{m}^{8}+\delta^{2}\left(Z_{m}-\frac{1}{m} a Z_{m}^{4}\right)^{2}
$$

Based on this expression, we can construct the control characteristic of the current stabilizer for various load resistances. The latter is characterized by the value of $\delta$, the possible maximum value of which is determined on the basis of the $\mathrm{I}-\mathrm{V}$ characteristic of the circuit of the ferromagnetic current stabilizer.

From the characteristics of the circuit of the ferromagnetic current stabilizer (Fig. 2), it can be seen that stabilization begins with $X_{m}=0,4$ and continues until $X_{m}=1,2$. Thus, if we assume $\mathrm{Y}_{\mathrm{m}}=1,2$, then the maximum voltage drop across the load should be determined by the following formula:

$$
Y_{n m}=\sqrt{Y_{m}^{2}+X_{m}^{2}}
$$

Knowing the value of the stabilization current, we determine $\delta=\frac{Y_{n m}}{Z_{m}}=0,44 ; \quad Z_{m}=2,5$

This means that in the stabilization mode, a change is allowed $\delta$ in the range from zero to 0.44 . In this case, the input voltage should be $=1.2$. Fig. 2 shows the control characteristics of the device for various values of active resistance, built on the basis of (7). For this case, the ratio of the installed power of the elements of the ferromagnetic current stabilizer to the load power is determined as follows:

$$
q=\frac{\Sigma|Q|}{P_{H}}=\frac{\left|Q_{m y}\right|+\left|Q_{k}\right|}{P_{u}}
$$

There $Q_{m y}$ - maximum power of the magnetic amplifier;

$Q_{k}$ - power of the compensating capacitor.

Considering that

$$
Q_{m y}=Z_{m y} * Y_{m} ; \quad Z_{m y}=3,75 ; \quad Y_{m}=1,2
$$

from (8) we obtain that $\mathrm{q} \approx 2$.

Thus, the installed power of the elements of the current stabilizer is more than 2 times higher than the load power. This indicator is more than two times less than that of the considered FTS [23-32].

For the case of active-inductive load based on the following circuit equation

$$
u=R_{\mu}\left(i_{c}+i_{\phi \ni}\right)+L \frac{d}{d t}\left(i_{c}+i_{\phi \ni}\right)+2 W \frac{d \phi}{d t}
$$

after simple transformations and introduction of normalized values, we obtain

$y=\delta\left(Z_{c}+Z_{\phi \supset}\right)+\gamma_{H} \frac{d \phi}{d \tau}\left(Z_{c}+Z_{\phi \supset}\right)+\frac{d \phi}{d \tau}$

Here

$$
\delta=\frac{L_{H} i_{\delta}}{2 W \phi_{\delta}} \quad Z_{c}=\frac{i_{c}}{i_{\delta}} \quad Z_{\phi \ni}=\frac{i_{\phi \ni}}{i_{\delta}}
$$

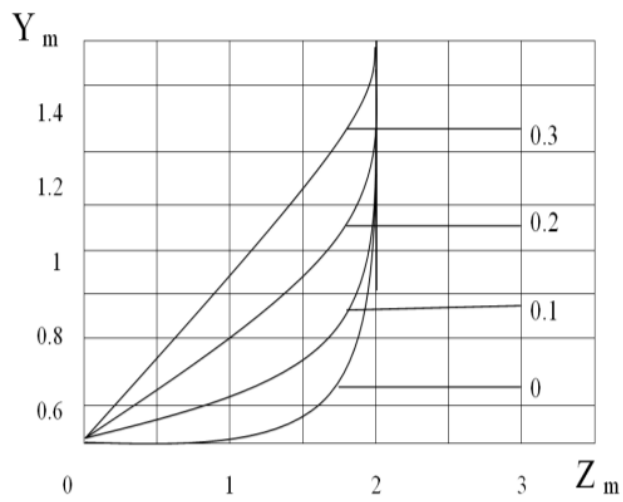

Fig. 2. Control characteristics for resistive load

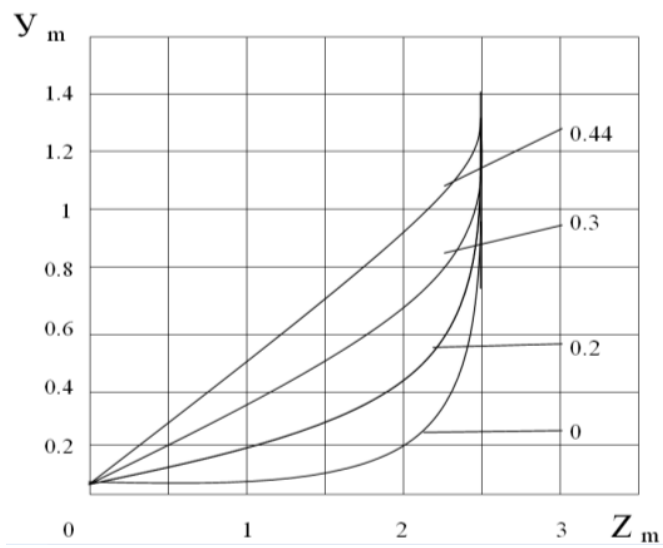

Fig. 3. Control characteristics for active-inductive load

Considering that:

$$
Z_{c}=\frac{1}{m} \frac{d^{2} x^{2}}{d \tau^{2}}
$$

$y=Y_{m} \cos (\tau+\varphi)$
$Q_{k}=Z_{m k}{ }_{x={ }_{m k} ;} \dot{X}_{m} \sin \frac{Z_{m}}{\tau} \quad z_{\phi \ni}=Z_{m \phi \ni} \sin \tau$

If we take the approximating function of the curve of simultaneous magnetization of a ferromagnetic element in the form (6), then after some transformations, we get:

$$
Y_{m}^{2}=\delta^{2}\left(Z_{m \phi \rho}-\frac{\alpha Z}{m}\right)^{2}+\left[\gamma_{H}\left(Z_{m \phi \rho}-\frac{\alpha Z_{m \phi \rho}^{4}}{m}\right)+\alpha Z_{m \phi \rho}^{4}\right]^{2}
$$

Based on the last dependency, given that 


$$
Z_{m c T}=Z_{m \phi \supset}-\frac{\alpha Z_{m \phi \jmath}^{4}}{b}
$$

we can build the regulating characteristics of the current stabilizer for different values (Fig. 3) of active-inductive load. For an active - capacitive load, the circuit equation is as follows;

$$
\frac{d u}{d t}=R_{H} \frac{d \phi}{d t}\left(i_{c}+i_{\phi \infty}\right)+\frac{i_{c}+i_{\phi o}}{C_{k}}+W \frac{d^{2} \phi}{d t^{2}}
$$

After a series of transformations, we have

$$
Y_{m}^{2}=\delta^{2}\left(Z_{m \phi s}-\frac{\alpha Z_{m \phi \rho}^{4}}{b}\right)^{2}+\left[\alpha Z_{m \phi s}^{4}-\gamma\left(Z_{m \phi s}-\frac{\alpha Z_{m \phi \rho}^{4}}{m}\right]^{2}\right.
$$

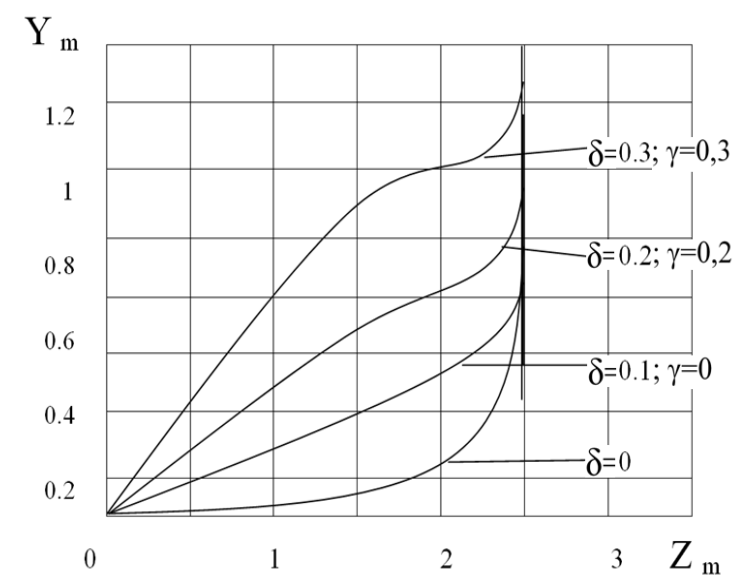

Fig. 4. Control characteristics for active-capacitive load

Here

$$
\gamma=\frac{i_{\delta}}{2 \omega^{3} W C_{H} \phi_{\delta}}
$$

Thus, expressions (12) and (13) differ from each other only in signs in front of the coefficients $\gamma_{\mathrm{H}}$ and $\gamma$, which are proportional to the inductive and capacitive resistance of the loads. In fig. 4. shows the nature of the change in the control characteristics for various values of complex loads. Whence, the active-capacitive load is favorable for the current stabilization mode, since the voltage stabilization range is wider in comparison with the inductive nature of the load, when the same values are taken $\delta$ and $\gamma$ [33-41].

\section{References}

1. L.A.Bessonov. Theoretical foundations of electrical engineering. Electrical circuits. Textbook 10th ed. $-\mathrm{M}$, Gardarmki 2002. 1638 p.

2. Volkov I.V., Gubarevich V.N., Isakov V.N., Boar V.P. Principles of construction and optimization of circuits of inductive-capacitive converters. Kiev: Naukova Dumka, 1981.-174 p.

3. F.A.Hoshimov, I.I.Bakhadirov, M.S.Kurbanbayeva, N.A.Aytbayev. Development of specific standards of energy consumption by types of produced products of the spinning product // RSES 2020. E3S Web of Conferences. 216 (2020) 01169. https://doi.org/10.1051/e3sconf/202021601169
4. F.A.Hoshimov,
I.I.Bakhadirov,
A.A.Alimov, M.T.Erejepov. Forecasting the electric consumption of objects using artificial neural networks // E3S Web of Conferences. $216 \quad 01170$. https://doi.org/10.1051/e3sconf/202021601170

5. R.Karimov, M.Bobojanov. Analysis of voltage stabilizers and non-contact relays in power supply systems // RSES 2020. E3S Web of Conferences. 216 (2020) 01162. https://doi.org/10.1051/e3sconf/202021601162

6. R.Karimov. Study of the state of the issue of increasing the quality of electric energy in the power supply systems // RSES 2020. E3S Web of Conferences. 216 (2020) 01163. https://doi.org/10.1051/e3sconf/202021601163

7. I.U.Rakhmonov, L.Nematov, N.N.Niyozov, K.M.Reymov, T.Yuldoshev. Power consumption management from the positions of the general system theory // ICMSIT-2020. Journal of Physics: Conference Series. 1515 (2020) 022054. doi:10.1088/1742-6596/1515/2/022054

8. I.U.Rakhmonov, F.A.Hoshimov. Development of an algorithm for evaluating the dominant factors that have the greatest impact on the energy intensity of products // ENERGY-21. E3S Web of Conferences. 209 (2020) 07018. https://doi.org/10.1051/e3sconf/202020907018

9. Usmanov E.G. Stability in a parallel resonant circuit with active load // RSES 2020. E3S Web of Conferences. 216 (2020) 01160. https://doi.org/10.1051/e3sconf/202021601160 10. Usmanov E.G., Khusanov B.M. Phase relations in resonant circuits with a wide falling section on the amplitude characteristic // RSES 2020. E3S Web of Conferences. 216 (2020) 01161. https://doi.org/10.1051/e3sconf/202021601161 11. I.U.Rakhmonov, K.M.Reymov and S.H.Dustova. Improvements in industrial energy rationing methods // MIP: Engineering-2020. E3S Web of Conferences. 862 (2020) 062070. doi:10.1088/1757-899X/862/6/062070

12. I.U.Rakhmonov, K.M.Reymov. Statistical models of renewable energy intermittency // RSES 2020. E3S Web of $\begin{array}{llll}\text { Conferences. } & 216 & \text { (2020) } & 01167 .\end{array}$ https://doi.org/10.1051/e3sconf/202021601167

13. I.U.Rakhmonov, N.N.Kurbonov. Analysis of automated software for monitoring energy consumption and efficiency of industrial enterprises // E3S Web of Conferences. $216 \quad 01178$. https://doi.org/10.1051/e3sconf/202021601178

14. F.A.Hoshimov, I.U.Rakhmonov, N.N.Niyozov. Technology to reduce energy costs in the electric steel melting shop // ENERGY-21. E3S Web of Conferences. 209 (2020) 07017. https://doi.org/10.1051/e3sconf/202020907017 15. A.Taslimov, F.Rakhimov, L.Nematov, N.Markaev, A.Bijanov, R.Yunusov. Economic load intervals for selecting $10 \mathrm{kV}$ cable cross-sections for agricultural consumers // CONMECHYDRO - 2020. IOP Conf. Series: Materials Science and Engineering. $883 \quad$ (2020) 012102. doi:10.1088/1757-899X/883/1/012102

16. A.Taslimov, M.Melikuziev, O.Matchonov, M.Ruzinazarov and M.Nasirov. Development of standard cable cross-sections of rural electrical networks // CONMECHYDRO - 2020. IOP Conf. Series: Materials Science and Engineering. $883 \quad$ (2020) 012105. doi:10.1088/1757-899X/883/1/012105

17. A.D.Taslimov, A.S.Berdishev, F.M.Rakhimov and A.A.Yuldashev. Optimal tendency of selecting cable crosssections for agricultural electrical networks // ICMSIT-2020. Journal of Physics: Conference Series. 1515 (2020) 022056. doi:10.1088/1742-6596/1515/2/022056 
18. K.M.Reymov, G.R.Rafikova, L.A.Nematov, Sh.Esemuratova. Existing condition and prospects of making power balance and managing load of electric consumers in uzbek power system // ENERGY-21. E3S Web of Conferences. $209 \quad 07015$. https://doi.org/10.1051/e3sconf/202020907015

19. A.D.Taslimov, F.M.Rakhimov, A.O.Norkulov, A.A.Yuldashev. Research of the optimum scale of standard sections of agricultural purpose lines // E3S Web of

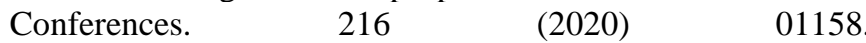
https://doi.org/10.1051/e3sconf/202021601158

20. A.D.Taslimov., M.V.Melikuziev, A.M.Najimova, A.A.Alimov. Economic load intervals for selection of cable sections for agricultural purpose // E3S Web of Conferences. 216 (2020)

01159.

https://doi.org/10.1051/e3sconf/202021601159

21. Dmitriy Bystrov, Toirov Olimjon, Mustafakulova Gulzoda, Yakubova Dilfuza NISS2020: Proceedings of the 3rd International Conference on Networking, Information

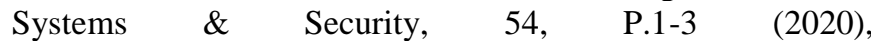
https://doi.org/10.1145/3386723.3387873

22. Olimjon Toirov, Allabergan Bekishev, Sardor Urakov and Utkir Mirkhonov E3S Web of Conferences 216, 01116 (2020), https://doi.org/10.1051/e3sconf/202021601116

23. Olimjon Toirov,Kamoliddin Alimkhodjaev, Nurali Pirmatov and Aziza Kholbutaeva E3S Web of Conferences 216 , 01119

(2020)

https://doi.org/10.1051/e3sconf/202021601119

24. Kamoliddin Alimkhodjaev, Olimjon Toirov, Mirzohid Taniev, Sharofiddin Alimkhodjaev Addressing Issues and Possibility of Introducing Renewable Energy Sources in the Conditions of Uzbekistan. JCR. 7(15), 1721-1728 (2020), doi:10.31838/jcr.07.15.231

25. Olimjon Toirov, Tulyagan Kamalov, Utkir Mirkhonov, Sardor Urokov, Dilnoza Jumaeva The mathematical model and a block diagram of a synchronous motor compressor unit with a system of automatic control of the excitation, E3S Web of Conferences, SUSE-2021 (2021)

26. Abduazizov N.A., Muzaffarov A., Toshow J.B., Juraev R.U., Zhuraev A.Sh. A complex of methods for analyzing the working fluid of a hydrostatic power plant for hydraulic mining machines // International Journal of Advanced Science and Technology. Vol. 29, No. 5s, (2020), pp. 852855

27. Baratov B., Toshov J., Baynazov U. Method of calculating the gear ratios of the cones of tricone drill bits // E3S Web Conf., Volume 201, 01012, 2020, Ukrainian School of Mining Engineering - 2020. https://doi.org/10.1051/e3sconf/202020101012

28. Haqberdiev A., Toshov J. Analysis of the control system of electric motors of the running gear of self-propelled mine cars used in complex mining and technological conditions // E3S Web of Conferences 216, 01135 (2020), Rudenko International Conference "Methodological problems in reliability study of large energy systems" (RSES 2020), https://doi.org/10.1051/e3sconf/202021601135

29. K.M.Reymov, G.Turmanova, S.Makhmuthonov, B.Uzakov. Mathematical models and algorithms of optimal load management of electrical consumers // E3S Web of $\begin{array}{llll}\text { Conf. } & 216 & \text { (2020) }\end{array}$ https://doi.org/10.1051/e3sconf/202021601166

30. Yu.M.Bobozhonov, K.M.Reymov, B.T.Seytmuratov,
T.Kh.Khakimov. Research of the dependence of the resistance of asynchronous generators with massive rotors on their design // RSES 2020. E3S Web of Conferences. 216 (2020) 01168. https://doi.org/10.1051/e3sconf/202021601168 31. A.N.Rasulov, M.R.Ruzinazarov, N.Toirova, T.Sh.Alibekova. Graphical-analytical method for constructing load characteristics // RSES 2020. E3S Web of Conferences. $\quad 216 \quad 01171$. https://doi.org/10.1051/e3sconf/202021601171

32. Rakhmonov I U, Reymov K M 2019 Mathematical Models and Algorithms of Optimal Load Management of Electricity Consumers J ENERGETIKA. Proceedings of CIS higher education institutions and power engineering association 62(6) pp 528-535 doi:10.21122/1029-7448-201962-6-528-535

33. Rakhmonov I U, Tovbaev A N, Nematov L A and Alibekova T Sh 2020 Development of forecasted values of specific norms for the issues of produced products in industrial enterprises Journal of Physics: Conference Series 1515 doi:10.1088/1742-6596/1515/2/022050

34. Rakhmonov I U, Nematov L A, Niyozov N N, Reymov K M and Yuldoshev T M 2020 Power consumption management from the positions of the general system theory Journal of Physics: Conference Series 1515 doi:10.1088/1742-6596/1515/2/022054

35. Rakhmonov I U, Reymov K M 2019 Regularities of change of energy indicators of the basic technological equipment of the cotton-cleaning industry Journal of Physics: Conference Series 1399 doi:10.1088/17426596/1399/5/055038

36. E.Usmanov, A.Rasulov, M.K.Bobojanov, R.Ch.Karimov. Non-contact voltage relay for switching windings of a boost transformer (E3S Web of Conferences, 139, 01079, 2019), https://doi.org/10.1051/e3sconf/201913901079

37. Karimov R.Ch., Bobojanov M.K., Rasulov A.N., Usmanov E.G. Controlled switching circuits based on nonlinear resistive elements (E3S Web of Conferences, 139, 01039, 2019), https://doi.org/10.1051/e3sconf/201913901039 38. Toshniyozov L.G., Toshov J.B. Theoretical and experimental research into process of packing in drilling. MIAB. Mining Inf. Anal. Bull. 2019;(11):139-151. [In Russ]. DOI: $10.25018 / 0236-1493-2019-11-0-139-151$.

39. Mannanov U., Toshov J., Toshniyozov L. Perspective Solutions for the Design of Drilling Tools // E3S Web of Conferences 105, 03027 (2019) IVth International Innovative Mining Symposium. DOI:10.1051/e3sconf/201910503027

40. Toshov J.B. The questions of the dynamics of drilling bit on the surface of well bottom// Arch. Min. Sci. - Poland. Vol. 61 (2016), № 2, P. 279-287. DOI 10.1515/amsc-20160020

41. Toshov Zh.B. Ways towards optimization of washout components of rock cutting tools // «GORNYI ZHURNAL»/«MINING JOURNAL», Moscow, 2016, № 2, pp. 21-24. DOI: http://dx.doi.org/10.17580/gzh. 